\title{
Norois
}

Environnement, aménagement, société

La Loire. Sociétés, risques, paysages, environnement

\section{Varagne (Michel), Le jour où la Loire débordera...}

Romorantin, Communication-Presse-Édition, 2003, 224 p. (29€)

\section{Denis Mercier}

\section{CpenEdition}

\section{Journals}

Édition électronique

URL : http://journals.openedition.org/norois/971

DOI : 10.4000/norois.971

ISBN : 978-2-7535-1540-6

ISSN : $1760-8546$

\section{Éditeur}

Presses universitaires de Rennes

\section{Édition imprimée}

Date de publication : 1 septembre 2004

Pagination : 144-145

ISBN : 978-2-7535-0054-9

ISSN : 0029-182X

\section{Référence électronique}

Denis Mercier, « Varagne (Michel), Le jour où la Loire débordera... », Norois [En ligne], 192 | 2004/3, mis en ligne le 26 août 2008, consulté le 23 septembre 2020. URL : http://journals.openedition.org/norois/ 971 ; DOI : https://doi.org/10.4000/norois.971

Ce document a été généré automatiquement le 23 septembre 2020

(c) Tous droits réservés 


\section{Varagne (Michel), Le jour où la Loire débordera...}

Romorantin, Communication-Presse-Édition, 2003, 224 p. (29€)

Denis Mercier

\section{RÉFÉRENCE}

Varagne (Michel), 2003. - Le jour où la Loire débordera..., Romorantin, CommunicationPresse-Édition, 224 p. $(29 €)$ 
1 À l'heure où la nouvelle loi sur les risques naturels (loi nº 2003-699 du 30 juillet 2003 dans son article 40) impose aux collectivités locales concernées, de prévoir des plans d'évacuation et d'organisation des secours, le livre de Michel Varagne arrive à point nommé. Il servira de base de travail et de réflexion pour les responsables publics (maires, services techniques, services de l'État...), mais aussi pour tous les riverains de la Loire, qui seront bien inspirés par la lecture de ce récit-fiction, pour le jour où...

2 Le cadre spatial de l'ouvrage est celui du Val de Loire, avec Orléans comme épicentre du récit. Le cadre temporel est celui d'une gestion de crise, avec la pré-

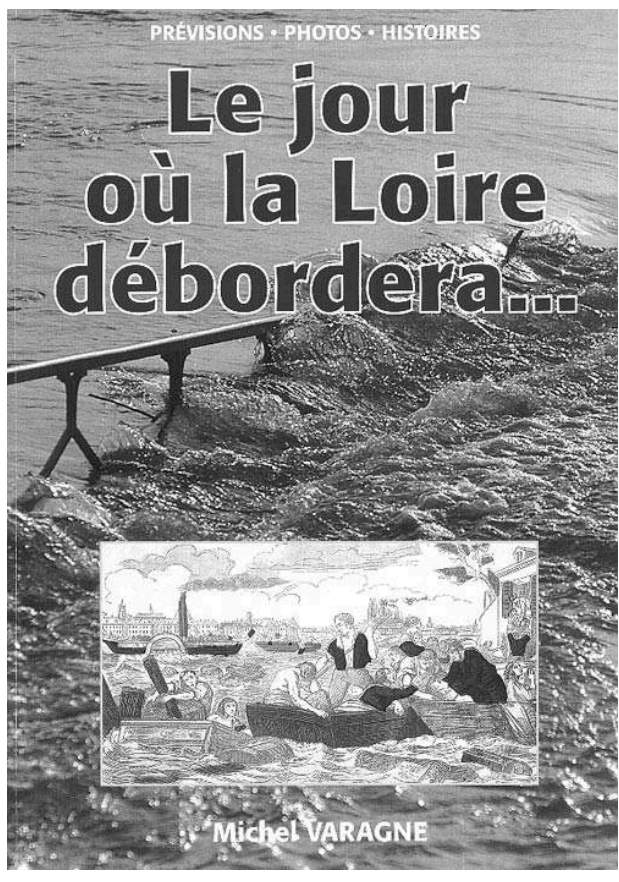
crise et la post-crise, qui se déroulerait un certain mois d'octobre, entre le 11 et le 23. L'auteur se garde bien de préciser l'année. Le problème au cœur de ce passionnant ouvrage n'est pas de savoir où et quand la Loire débordera, car l'événement surviendra un jour, mais que faire face aux enjeux d'un tel événement. Et l'ampleur du travail n'est pas mince. L'auteur se sert de nombreux documents officiels et rappelle qu'entre Nevers et Angers, pas moins de 240 communes recouvrent une zone inondable, dont 50 ont la totalité de leur territoire concernée ; soit environ 115000 logements, 290000 personnes, 13600 entreprises, 1600 équipements collectifs... L'auteur évoque au passage les grandes crues historiques, notamment les « trois glorieuses » de 1846, 1856, 1866, mais également celles 1707, 1709, 1710, 1711, 1904, 1907, 1910, 1923, 1980, 2001. La liste n'est ni exhaustive, ni close... Certaines sont illustrées par des cartes postales.

3 L'ouvrage se lit fort bien, sous la plume d'un journaliste de « La République du Centre " habitué aux bons mots, dont il abuse parfois. Les géographes pourront regretter l'absence de cartographie à grande échelle centrée sur Orléans.

4 Mais cet ouvrage demeure d'une grande utilité pour développer la culture du risque, favoriser une bonne gestion des crises par anticipation, surtout quand il faut évacuer des zones inondables urbanisées. Et si, on peut l'espérer, la lecture de cette fiction rendait moins pressante la demande individuelle de construction en zone inondable, et donnait plus de courage aux responsables politiques pour refuser d'aggraver une situation déjà aussi préoccupante humainement que financièrement coûteuse pour les contribuables de ce pays ? Entre 1982 et 2002, la caisse centrale de réassurance a évalué à 4,8 milliards d'euros le coût des inondations en France, soit 240 millions d'euros par an. Mais comme l'a souligné Freddy Vinet dans une étude minutieuse sur les inondations dans la France méditerranéenne ${ }^{1}$, ce chiffre doit être multiplié par deux car il ne comptabilise pas les dommages aux biens publics non assurés (infrastructures...), les dommages agricoles et les pertes restées à la charge des particuliers (franchises...). Il faut y ajouter également le coût d'entretien des 
infrastructures (digues, barrages...). Une facture totale proche de 630 millions d'euros par an. À méditer...

\section{NOTES}

1. Vinet (F.), 2003. - Géographie des risques. Crues et inondations dans la France méditerranéenne. Les crues torrentielles des 12 et 13 novembre 1999 (Aude, Tarn, Pyrénéesorientales, Hérault), Nantes, Éditions du Temps, 224 p.

INDEX

Index géographique : France, Loire (fleuve et vallées) 